\title{
The prevalence of urinary incontinence in elderly Canadians and its association with dementia, ambulatory function, and institutionalization
}

\author{
Steinar Hunskaar, MD, $\mathrm{PhD}^{1}$, Truls Østbye, MD, $\mathrm{MPH}^{2}$, and Michael J. Borrie, $\mathrm{MD}^{3}$ \\ ${ }^{l}$ Division for General Practice, Department of Public Health and Primary Health Care, \\ University of Bergen, Norway \\ ${ }^{2}$ Department of Epidemiology and Biostatistics and Department of Family Medicine, \\ University of Western Ontario, London, Ontario, Canada \\ ${ }^{3}$ Division of Geriatric Medicine, University of Western Ontario, London, Ontario, Canada \\ Correspondence to: Professor Steinar Hunskaar, Division for General Practice, University of Bergen, Ulriksdal 8c, N-5009 Bergen, Norway \\ Telephone +4755586100 Telefax +4755586130 E-mail steinar.hunskar@isf.uib.no
}

\begin{abstract}
Study objectives: Data from The Canadian Study of Health and Aging are analysed for prevalence of urinary incontinence, and its association with dementia, ambulatory function, and institutionalization.

Design and setting: Population based multi-centre survey with stratified random sampling all over Canada. Randomly selected persons aged 65 and over were interviewed. Those having cognitive impairment ( $\mathrm{n}=1614)$, a randomly selected sample of those without $(\mathrm{n}=731)$ and an institutional sample $(\mathrm{n}=1255)$ underwent clinical assessment.

Main results: Overall, $16.9 \%$ of the women and $8.0 \%$ of the men reported incontinence, the numbers for daily incontinence were $7.0 \%$ and $5.2 \%$ respectively. The prevalence increased by age, severity of dementia, and decreasing ambulatory function. It is calculated that $69 \%$ of elderly men and $73 \%$ of elderly women with any incontinence live in the community. $31 \%$ of the male and $32 \%$ of the female patients have some kind or severity of dementia, and $21 \%$ of the men and $27 \%$ of the women have decreased ambulatory function. One half of the persons with incontinence live in the community, with no cognitive or ambulatory impairment.

Conclusion: Urinary incontinence is a prevalent condition among the elderly, and is associated with age, dementia, and ambulatory function. Although incontinence is highly prevalent among institutionalized persons, the majority of persons with incontinence live in the community.
\end{abstract}

Key words: urinary incontinence; dementia; institutionalization; community-institutional relations

\section{INTRODUCTION}

Urinary incontinence is a common, distressing, and costly health problem in the elderly. Many studies have investigated the prevalence of urinary incontinence, most of them only in the female population. Even in comparable settings and age groups, widely different results have been observed. The prevalence of any urinary incontinence among older adults (age $70+$ ) living in the community is likely to be as high as $30 \%$, while weekly or more frequent urine loss may be experienced by $5-10 \%(1-5)$. In nursing homes and other long-term care institutions the prevalence ranges from $30 \%$ to $65 \%$ (6-8). Different definitions of urinary incontinence and data collection methods may have contributed to the differences in prevalence (9). Furthermore, population based studies may or may not include institutionalized persons, and the "threshold" for institutionalization varies from country to country.

Urinary incontinence in the elderly can be caused by or associated with a range of medical conditions. Post-menopausal hormonal changes and anatomical changes in the pelvic organs are important in women, prostatic disease contributes in men, and stroke, neurological and musculoskeletal conditions are of importance in both genders (10-12). Cognitive function and mobility have attracted attention as predictors for urinary incontinence, with incontinence found to be associated with dementia, poor mobility, and poor physical health in general $(7,13-15)$. Correspondingly, incontinence has been found to be a good predictor for institutionalization (16-19).

The interactions between urinary incontinence and dementia, ambulatory function, and institutionali- 
zation, however, are not fully understood. Most earlier studies have not investigated all factors, the studies have often been small with low statistical power, and thus it has not been possible to determine the relative influence of the factors. It must also be emphasized that correlational data cannot determine causal direction nor whether the influence is direct, indirect or spurious (7).

The Canadian Study of Health and Aging (CSHA) is a Canada-wide population based multi-centre study, with stratified random sampling of subjects and institutions, and with a special focus on the epidemiology of Alzheimer's disease and other dementias. It also surveyed disabilities, general well-being, and common health problems such as urinary incontinence. The study had both a community based and an institution based arm. In the present investigation we analysed data from the CSHA to determine the prevalence of incontinence in the elderly, with emphasis on the association with dementia, ambulatory function, and institutionalization, in both men and women.

\section{MATERIAL AND METHODS}

The study methods of the CSHA have been published in detail elsewhere (20). Below, only the methodology and subject selection directly relevant to the present article are outlined. Data collection began in February 1991 and was completed by March 1992.

\section{Subjects and institutions}

In the community, randomly selected persons aged 65 and over were interviewed $(n=8949)$. The samples were obtained from provincial health insurance plans or similar sources. The randomization was stratified by gender and age groups (65-74, 75-84, and 85 years and over) with oversampling in the older groups. The questionnaire included demographic information, current health problems, social support, and a screening test for dementia. Those screening positive for cognitive impairment $(n=1614)$ and, in addition, a randomly selected sample of those screening negative $(n=731)$ were asked to undergo clinical assessment.

The institutional sample $(n=1255)$ comprised subjects in nursing homes, chronic care facilities, and collective dwellings such as convents. This sample was stratified by institution size, and individuals in the selected institutions were then chosen randomly.

The clinical examination took 4 to 5 hours and was held in a hospital or clinic. A study nurse administered several questionnaires and tests. Second, a psychometrician administered a neuropsychological test battery (later reviewed by a neuropsychologist), and third, a physician reviewed the information collected, and performed a mental status assessment as well as a physical and neurological examination.

\section{Urinary incontinence}

Urinary incontinence data was gathered from two sources: a clinical examination and a caregiver questionnaire. If the subject was incapable of answering, the questions were directed to the subject's caregiver, who was defined as the person being the most responsible for the day-to-day provision of care of the subject; paid professionals, family members or friends were included. The questions to the subject were: "Do you have any difficulty with incontinence of urine?" If "Yes", "Is it daily, less than daily but more than once a month, or less than once a month?" The caregiver was asked to choose the frequency of incontinence from a cue card ("never", "rarely", "sometimes", "frequently" or "all of the time").

Based on a combination of the available data on urinary incontinence each subject was classified as 1) continent, 2) having daily incontinence, 3) having less than daily incontinence, or 4) unknown. Subjects with an indwelling catheter were classified as having daily incontinence. Those who were incontinent less than once a month (data from the clinical examination), were considered continent for the statistical analyses.

\section{Cognition}

Cognition was assessed using a four part clinical examination, including the use of the modified MiniMental State Examination, a battery of neuropsychological tests, and a thorough assessment by a physician. Details are published elsewhere (20). Hematological and biochemical tests were done where appropriate. Case conferences were held to arrive at a consensus diagnosis in one of the following categories: 1) no cognitive loss, 2) cognitive impairment but no dementia (CIND), 3) Alzheimer's disease, 4) vascular dementia or other specific dementia or 5) unclassified. The diagnostic criteria followed the DSM-III-R and National Institute of Neurological and Communicative Disorders and Stroke/Alzheimer's Disease and Related Disorders Association's criteria for dementia $(21,22)$. The severity of dementia was rated as 1) mild, 2) moderate, or 3) severe.

\section{Ambulatory function}

The subject's need for assistance and his/her indoor ambulatory function was assessed by the question "Can you/(name of subject) walk 1) without help (except for cane)" or 2) "with some help (from a person or with the use of a walker, crutches etc.)", or 3) "are you/is he/she completely unable to walk?"

\section{Statistical analysis}

The prevalence of urinary incontinence was estimated by gender, age groups, cognitive and ambulatory function, and by institutionalization, using weights based on the 1991 Canadian Census Enumerations. Logistic 
regression was used in order to determine the relative risk (approximated by the adjusted odds ratio) of incontinence depending on the variables listed above. $95 \%$ confidence limits were calculated from the logistic regression model.

\section{Ethics and consent}

Ethical approval for the CSHA was obtained from the ethics review board in each of the 18 study centres. In all parts of the study the subjects gave their written consent. For incompetent persons proxy consent was obtained from the most responsible family member or from the person legally responsible for the subject.

\section{RESULTS}

The results are based on available data from 1876 women (Table 1) and 1038 men (Table 2). The tables show the prevalence of daily and less than daily urinary incontinence by age group, residence, severity of dementia, and ambulatory function. Overall, 16.9\% of the women and $8.0 \%$ of the men reported any incontinence, the numbers for daily incontinence were $7.0 \%$ and $5.2 \%$ respectively. For both men and women the prevalence increased by age, severity of dementia, and decreasing ambulatory function (bivariate analy- ses). Female patients in institutions had nine times and male patients ten times higher prevalences of daily urinary incontinence compared to the community living elderly. The logistic regression analysis showed somewhat different results in men and women. In women, we found a slight effect of age, a clear effect of increasing severity of dementia, and of decreasing ambulatory function (Table 1). In men, we found a clear effect of dementia and decreased ambulatory function (Table 2).

Table 3 shows the distributions of men and women with regard to age group, residence, dementia, and ambulatory function. It can thus be calculated that $69 \%$ of men and $73 \%$ of women with any incontinence live in the community. $31 \%$ of the male and $32 \%$ of the female patients have some kind or severity of dementia (CIND excluded), and $21 \%$ of the men and $27 \%$ of the women have decreased mobility. $50 \%$ and $48 \%$ of men and women with any urinary incontinence, respectively, live in the community, with no cognitive or ambulatory impairment.

\section{DISCUSSION}

This study shows prevalences of urinary incontinence among elderly men and women about the median level

Table 1. Prevalence of urinary incontinence in Canadian women 65 years and over, by age group, dementia severity, residence, and ambulatory function. $n=$ the number of women in each analysis. Adjusted odds ratios (OR) with $95 \%$ confidence intervals (CI) were calculated by logistic regression analysis $(\mathrm{n}=1477)$. Weighted data (see methods for description). $\mathrm{CIND}=$ Cognitive impairment but no dementia.

\begin{tabular}{|c|c|c|c|c|c|}
\hline & \multicolumn{3}{|c|}{ Prevalence of urinary incontinence $(\%)$} & \multirow[b]{2}{*}{ OR } & \multirow[b]{2}{*}{$95 \% \mathrm{CI}$} \\
\hline & Daily & Less than daily & Unknown $^{*}$ & & \\
\hline Overall $(\mathrm{n}=1876)$ & 7.0 & 3.9 & 6.0 & & \\
\hline \multicolumn{6}{|l|}{ Age group, $y r(n=1876)$} \\
\hline $65-74$ & 2.4 & 2.6 & 4.4 & Ref. & \\
\hline $75-84$ & 9.4 & 5.6 & 8.2 & 2.7 & $1.8-4.1$ \\
\hline$\geq 85$ & 23.5 & 5.7 & 7.4 & 2.6 & $1.4-4.9$ \\
\hline \multicolumn{6}{|l|}{ Residence $(\mathrm{n}=1876)$} \\
\hline Community & 4.1 & 3.5 & 5.9 & Ref. & \\
\hline Institution & 36.9 & 7.5 & 6.3 & 1.4 & $0.6-3.0$ \\
\hline \multicolumn{6}{|c|}{ Severity of dementia $(n=1865)$} \\
\hline Normal & 3.4 & 3.0 & 4.8 & Ref. & \\
\hline Mild & 10.5 & 5.1 & 0.5 & 1.2 & $0.5-3.2$ \\
\hline Moderate & 24.8 & 10.2 & 11.1 & 4.0 & $1.9-8.2$ \\
\hline Severe & 63.5 & 10.5 & 9.3 & 12.6 & $4.6-34.4$ \\
\hline CIND & 7.0 & 5.1 & 10.2 & 1.2 & $0.7-2.1$ \\
\hline \multicolumn{6}{|c|}{ Ambulatory function $(\mathrm{n}=1581)$} \\
\hline Independent & 4.1 & 3.7 & 5.0 & Ref. & \\
\hline Partially dependent & 13.5 & 5.8 & 17.6 & 1.3 & $0.6-2.5$ \\
\hline Totally dependent & 75.3 & 4.5 & 7.8 & 7.1 & $2.2-23.2$ \\
\hline
\end{tabular}

*Incontinent, but unknown frequency. 
Table 2. Prevalence of urinary incontinence in Canadian men 65 years and over, by age group, dementia severity, residence, and ambulatory function. $\mathrm{n}=$ the number of persons in each analysis. Adjusted odds ratios (OR) with $95 \%$ confidence intervals (CI) were calculated by logistic regression analysis $(\mathrm{n}=856)$. Weighted data (see methods for description). CIND= Cognitive impairment but no dementia.

\begin{tabular}{|c|c|c|c|c|c|}
\hline & \multicolumn{3}{|c|}{ Prevalence of urinary incontinence (\%) } & \multirow[b]{2}{*}{ OR } & \multirow[b]{2}{*}{$95 \% \mathrm{CI}$} \\
\hline & Daily & Less than daily & Unknown $^{*}$ & & \\
\hline Overall (n=1038) & 5.2 & 1.4 & 1.4 & & \\
\hline \multicolumn{6}{|l|}{ Age group, yr (n=1038) } \\
\hline $65-74$ & 4.2 & 1.4 & 0.5 & Ref. & \\
\hline $75-84$ & 5.3 & 1.0 & 2.2 & 0.7 & $0.4-1.4$ \\
\hline$\geq 85$ & 14.8 & 3.6 & 6.4 & 1.6 & $0.6-4.2$ \\
\hline \multicolumn{6}{|l|}{ Residence $(n=1038)$} \\
\hline Community & 3.6 & 1.3 & 1.0 & Ref. & \\
\hline Institution & 36.8 & 4.7 & 8.8 & 3.0 & $0.9-10.3$ \\
\hline \multicolumn{6}{|c|}{ Severity of dementia $(n=1032)$} \\
\hline Normal & 4.1 & 1.1 & 0.5 & Ref. & \\
\hline Mild & 10.8 & 3.8 & 8.1 & 1.9 & $0.5-6.9$ \\
\hline Moderate & 24.6 & 6.0 & 3.7 & 3.5 & $1.3-10.7$ \\
\hline Severe & 64.1 & 6.7 & 10.1 & 10.1 & $1.8-55.9$ \\
\hline CIND & 2.1 & 1.5 & 2.8 & 0.4 & $0.2-1.0$ \\
\hline \multicolumn{6}{|c|}{ Ambulatory function $(\mathrm{n}=899)$} \\
\hline Independent & 3.8 & 1.3 & 1.0 & Ref. & \\
\hline Partially immobile & 17.1 & 4.9 & 3.9 & 1.8 & $0.5-7.0$ \\
\hline Totally immobile & 72.2 & 4.3 & 7.0 & 6.4 & $1.1-37.6$ \\
\hline
\end{tabular}

*Incontinent, but unknown frequency

Table 3. Percentage of all Canadian men and women, 65 years and over, by age group, residence, dementia severity, and ambulatory function. Weighted data (see methods for description).

\begin{tabular}{|c|c|c|}
\hline Variable & Men & Women \\
\hline Population N & $1,329,000$ & $1,838,000$ \\
\hline Sample n & 1038 & 1876 \\
\hline Age group, year & $\%$ & $\%$ \\
\hline $65-74$ & 64.0 & 56.7 \\
\hline $75-84$ & 29.5 & 32.6 \\
\hline$\geq 85$ & 6.5 & 10.7 \\
\hline \multicolumn{3}{|l|}{ Residence } \\
\hline Community & 95.0 & 91.3 \\
\hline Institution & 5.0 & 8.7 \\
\hline \multicolumn{3}{|l|}{ Severity of dementia } \\
\hline Normal & 72.4 & 76.8 \\
\hline Mild & 2.4 & 2.6 \\
\hline Moderate & 2.6 & 3.8 \\
\hline Severe & 1.4 & 3.4 \\
\hline CIND & 21.2 & 13.4 \\
\hline \multicolumn{3}{|l|}{ Ambulatory function } \\
\hline Independent & 96.6 & 91.0 \\
\hline Partially dependent & 2.0 & 6.3 \\
\hline Totally dependent & 1.4 & 2.7 \\
\hline
\end{tabular}

of studies of the general population (1-5). We also confirm the association between incontinence and impaired cognition and ambulatory function. When other factors are controlled for, institutionalization in itself does not seem to be a major factor associated with incontinence. We have also been able to calculate the distribution of incontinent persons in the community, and some of the comorbidity, factors that are seldom investigated.

The CSHA succeeded in administering a complex protocol to a large national sample of elderly Canadians. The response rates compare favourably with those in other surveys, and the random sampling of both subjects and institutions across the country is a major strength of the study (20). The study also covers both community dwelling and institutionalized persons, thus limiting the problems of regional differences in admittance policies. As the study included several relevant explanatory variables, we were able to take a multivariate approach determining their combined contribution to urinary incontinence, rather than bivariate associations already described in the literature. A comprehensive discussion of the representativeness of the subjects is found elsewhere (20).

The validity of the data concerning dementia, ambulation and institutionalization is strong. Some 
limitations, however, may be present in the incontinence data. The primary objective of the CSHA was not to study incontinence, thus it did not include a comprehensive assessment of incontinence symptoms, severity, or diagnostic subgroups. We combined data from more than one source (physician and caregiver) in order to improve the reliability of the prevalence data. The data should be at least as valid as population survey data, which is the most commonly published.

Most studies done in both genders have revealed that women over 60 have a prevalence of urinary incontinence at least twice as high as that of men (2). This difference is supported by our findings. A logistic regression model including both sexes (results not shown) did not suggest that this difference could be explained by the variables considered in our study. Thus other factors must explain the sex difference. From a clinical point of view, female and male incontinence are often considered to be totally different conditions because the causes and mechanisms differ.

Like dementia, urinary incontinence is assumed to be an important factor and predictor for institutionalization in the elderly $(19,25)$. In our bivariate analyses the prevalences of incontinence in institutions were ninefold and tenfold higher in women and men respectively when compared with community dwelling persons. However, the multivariate analysis revealed a statistically non-significant difference for both women and men, showing that when other factors are controlled for, there is no evidence for higher prevalence of female incontinence in institutions compared to the community.

Ambulatory function, measured in different ways, has been shown to be strongly associated with urinary incontinence, especially in institutions $(7,13,26)$. Our data support this association, as we found a "dosedependent" relationship to prevalence or odds ratio for urinary incontinence in men and women. We do not know much about the mechanisms for this association, but the finding may raise the question of incontinence as a partially "iatrogenic" condition, if inability to provide mobility assistance is present in institutions (13). The finding also emphasizes the importance of walking assistance as part of incontinence management programs in institutions.

Dementia has been consistently found to be associated with urinary incontinence $(7,27,28)$, but the relative importance of this factor has not been established. One study found that independence in walking ability was the best predictor of incontinence in an institution, followed by cognitive ability (13). Our community based data indicate that severity of dementia and impaired ambulatory function are the factors most strongly associated with incontinence.

In conclusion, we have been able to assess the prevalence of urinary incontinence and analyse the association with important residence and morbidity factors. In addition, we have shown where the incontinent population of elderly is to be found in the community, and the major comorbidity that exists. Such knowledge is of great importance both in a clinical and a public health perspective.

\section{ACKNOWLEDGEMENTS}

The data reported in this article were collected as part of the Canadian Study of Health and Aging, a project coordinated through the University of Ottawa and the Laboratory Centre for Disease Control. The study was funded by the Seniors' Independence Research Program, with funds administered by the National Health Research and Development Program (project 6606-3954-MC(S)). Additional funding was provided by the Division of Aging and Seniors, Health Canada. The study was coordinated through the University of Ottawa and the federal government's Laboratory Centre for Disease Control. Thanks to Elizabeth Sykes for data analysis and coordination. The analysis of the urinary incontinence data was also supported by a grant from the Norwegian Medical Research Council to Professor Hunskaar.

\section{REFERENCES}

1. Sandvik H, Hunskaar S, Seim A, Hermstad R, Vanvik A, Bratt H. Validation of a severity index in female urinary incontinence and its implementation in an epidemiological survey. J Epidemiol Community Health 1993; 47: 497-9.

2. Herzog AR, Fultz NH. Prevalence and incidence of urinary incontinence in community-dwelling populations. J Am Geriatr Soc 1990; 38: 273-81.

3. Brocklehurst JC. Urinary incontinence in the community - analysis of a MORI poll. BMJ 1993; 306: 832-4.

4. Diokno AC, Brock BM, Brown MB, Herzog AR. Prevalence of urinary incontinence and other urological symptoms in the noninstitutionalized elderly. J Urol 1986; 136: 1022-5.

5. Kok AL, Voorhorst FJ, Burger CW, van Houten P, Kenemans P, Janssens J. Urinary and faecal incontinence in community-residing elderly women. Age Ageing 1992; 21: 211-5.

6. Mohide EA. The prevalence and scope of urinary incontinence. Clin Geriatr Med 1986; 2: 639-55.

7. Borrie MJ, Davidson HA. Incontinence in institutions: costs and contributing factors. Can Med Assoc J 1992; 147: $322-8$ 
8. Borrie MJ, Ostbye T, Morin D, Hunskaar S. Urinary and fecal incontinence in Canadian long-term care institutions: Prevalence and associated factors. Clin Invest Med 1995; 18 (Suppl B): B58.

9. Abrams P, Blaivas JG, Stanton SL, Andersen JT. The standardisation of terminology of lower urinary tract function. The International Continence Society Committee on Standardisation of Terminology. Scand J Urol Nephrol 1988; 114 (Suppl): 5-19.

10. DuBeau CE, Resnick NM. Evaluation of the causes and severity of geriatric incontinence. A critical appraisal. Urol Clin North Am 1991; 18: 243-56.

11. Yarnell JWG, St. Leger AS. The prevalence, severity and factors associated with urinary incontinence in a random sample of the elderly. Age Ageing 1979; 8: 81-5.

12. Yu LC, Rohner TJ, Kaltreider DL, Hu TW, Igou JF, Dennis PJ. Profile of urinary incontinent elderly in longterm care institutions. J Am Geriatr Soc 1990; 38: 433-9.

13. Jirovec MM, Wells TJ. Urinary incontinence in nursing home residents with dementia: the mobility-cognition paradigm. Appl Nurs Res 1990; 3: 112-7.

14. Ouslander JG, Morishita L, Blaustein J, Orzeck S, Dunn S, Sayre J. Clinical, functional, and psychosocial characteristics of an incontinent nursing home population. J Gerontol 1987; 42: 631-7.

15. Davidson HA, Borrie MJ, Crilly RG. Copy task performance and urinary incontinence in Alzheimer's disease. J Am Geriatr Soc 1991; 39: 467-71.

16. O'Donnell BF, Drachman DA, Barnes HJ, Peterson KE, Swearer JM, Lew RA. Incontinence and troublesome behaviors predict institutionalization in dementia. J Geriatr Psychiatry Neurol 1992; 5: 45-52.

17. Seidel GK, Millis SR, Lichtenberg PA, Dijkers M. Predicting bowel and bladder continence from cognitive status in geriatric rehabilitation patients. Arch Phys Med Rehabil 1994; 75: 590-3.

18. Ouslander JG, Zarit SH, Orr NK, Muira SA. Incontinence among elderly community-dwelling dementia patients. Characteristics, management, and impact on caregivers. J Am Geriatr Soc 1990; 38: 440-5.

19. Knopman DS, Kitto J, Deinard S, Heiring J. Longitudinal study of death and institutionalization in patients with primary degenerative dementia. J Am Geriatr Soc 1988; 36: 108-12.

20. Canadian Study of Health and Aging: Study methods and prevalence of dementia. Can Med Assoc J 1994; 150: 899-913.

21. Diagnostic and Statistical Manual of Mental Disorders, 3rd edn. Washington, D.C.: American Psychiatric Association, 1987.

22. McKhann G, Drachman D, Folstein M, et al. Clinical diagnosis of Alzheimer's disease: Report of the NINCDS-ADRDA Work Group under the auspices of Department of Health and Human Services Task Force on Alzheimer's Disease. Neurology 1984; 34: 939-44.

23. Vetter NJ, Jones DA, Victor CR. Urinary incontinence in the elderly at home. Lancet 1981; ii: 1275-7.

24. Feneley RC, Shepherd AM, Powell PH, Blannin J. Urinary incontinence: prevalence and needs. $\mathrm{Br} J$ Urol 1979; 51: 493-6.

25. Ekelund P, Rundgren A. Urinary incontinence in the elderly with implications for hospital care consumption and social disability. Arch Gerontol Geriatr 1987; 6: 11-8.

26. Morris A, Browne G, Saltmarche A. Urinary incontinence: correlates among cognitively impaired elderly veterans. J Gerontol Nurs 1992; 18: 33-40.

27. Ouslander JG, Uman GC, Urman HN, Rubenstein LZ. Incontinence among nursing home patients: clinical and functional correlates. $J$ Am Geriatr Soc 1987; 35: 324-30.

28. Ouslander JG, Palmer MH, Rovner BW, German PS. Urinary incontinence in nursing homes: incidence, remission and associated factors. $J$ Am Geriatr Soc 1993; 41: 1083-9. 